\title{
Preface
}

\section{Our Earth Matters: Pathways to a Better Common Environmental Future - Part 2}

\author{
Bharat H. Desai \\ Editor-in-Chief \\ Professor of International Law and Jawaharlal Nehru Chair in International Environmental Law, \\ Centre for International Legal Studies, School of International Studies, Jawaharlal Nehru University, New Delhi
}

It is a great pleasure and privilege to be invited to serve as Editor-in-Chief of the iconic Environmental Policy \& Law (EPL). It has come amidst global disruption and trauma caused since early 2020 by the unprecedented Covid-19 pandemic. In the wake of an innocuous Skype call for consultation, Marten Stavenga, IOS Press colleague, accepted my idea for a special issue to celebrate $50^{\text {th }}$ anniversary of EPL. He promptly invited me on 08 June 2020 to be the Guest Editor of the EPL Special Issue. It is also touching that the sagacious Director of IOS Press, reposed trust in me first as the Managing Editor and then as the Editor-in-Chief.

The EPL invitation came as a reason (निमित्त) to extricate me from the morass of investing enormous time, energy and creativity in grooming persons around me and in safeguarding my home turf. As a corollary to my two decades of scholarly works on global environmental governance, the EPL role has set me on to the wider path of finding scholarly and policy-relevant answers to the crisis arising from the human developmental predicament that has imperiled our only abode of planet earth.

\section{Our Earth Matters}

At this unveiling of the EPL Special Issue with the theme of Our Earth Matters, I recall my early publication, as a doctoral scholar, on "Destroying the Global Environment" (International Perspectives, Ottawa, Nov./Dec. 1986, pp.27-29), that sought to underscore the "human quest for development seriously threatens our fragile ecosystem". The resultant global environmental regulatory process has come a long way since warning bells rung by works such as Rachel Carson's Silent Spring (1962), Club of Rome's report on The Limits to Growth (1972), Richard Falk's This Endangered Planet (1972) and Barbara Ward \& Rene Dubos's Only One Earth (1972), prior to the first UN Conference on Human Environment (Stockholm).

We now stand at a remarkable threshold to mark fifty years of the EPL mission. It is a humbling moment since I have literally grown with EPL, having been invited in 1999 from my perch at University of Bonn, by the late founding editor Wolfgang Burhenne, to make scholarly contribution on 'institutionalization'. I also do vividly recall Wolfgang's zest to sit with me to calibrate the title of my Bonn Open Lecture (26 October 2005) as "UNEP: A Global Environmental Authority?" (EPL, vol.36.4-5, 2006). I often had the privilege of being affectionally hosted by Wolfgang and Francoise at their serene home on the outskirts of the City of Bonn. After Francoise's early departure, the affection lasted till I met Wolfgang for the last time on 26 July 2016 in the lobby of Hotel Maritim Bonn. He encouraged me to stick to my futuristic work with a forecast that the upgrade of UNEP into a UN 'specialized agency' for the environment (UNEPO) will materialize.

Hence, IOS Press's entrustment of the EPL editorship has led me to follow in the footsteps of Wolfgang's legendary energy, skills and encyclopedic knowledge. I also need to recall long association with feisty colleague Tomme Young who took care of EPL in the aftermath of Wolfgang' demise on 06 January 2017. She valued to duly publish my ideas and proposals in EPL. Editorship of a journal, like scholarly works, takes place on the 
shoulders of the previous contributors. Hence, it is humbling to don this new mantle.

\section{Anthropocene Epoch}

We now live in the Anthropocene as the new geological epoch (recognized on 21 May 2019), with an 'unmistakable imprint of human activities'. That, in turn, calls for a new human prism for the care, maintenance and 'trusteeship of the planet'. It is an appropriate occasion to reflect upon the course traversed in the past fifty years only to earnestly look ahead to seek answers for our better common environmental future. It raises some pertinent questions: What lies in store for us in the next three quarters of the $21^{\text {st }}$ century? How do we manage our profligate life styles, heavy resource extraction-based production processes and wasteful patterns of consumption so as not to endanger the very survival of life on planet earth in general and the future of humankind in particular?

It calls for serious prognosis to make sense of the concerted global environmental law-making and institution-building processes comprising the normative approach at work, global conferencing technique followed by the United Nations General Assembly (1972, 1992, 2002, 2012 and the forthcoming 2022 event), application and efficacy of the basic legal underpinnings of international law to the environmental challenges, actual working of the giant treaty-making enterprise, and quest for a robust global environmental governance architecture.

EPL's $50^{\text {th }}$ anniversary remarkably precedes the $50^{\text {th }}$ anniversary of the 1972 Stockholm Conference in 2022. Thus, it sets us on the road to yet another defining moment for a futuristic gaze to make sense of the perennial "predicament of mankind" to "devise effective responses" for the "world problematique" (The Limits to Growth, 1972). In turn, in calls for an honest introspection as regards what have we attained during the past 50 years journey comprising giant regulatory process, use of innovative tools and techniques, art and craft of lawmaking. Has it brought about changes in human mindsets, jettisoning of greed and defining our needs? What could be the new ideas, approaches, processes, regulatory tools and institutional structures to address the "world problematique"? It still continues to haunt us after fifty years.

\section{Exploring the Future Pathways}

It is in this context that the EPL Special Issue comprises invited perspectives from outstanding scholars from the five continents to probe the existing global regulatory processes, approaches and instruments for the protection of the global environment. It enjoins us to ponder over the reckless destruction of our sacred spaces, endangering of plants and animal species, poisoning of land, atmosphere, water resources and the oceans (predicted to have more plastics than fish by 2050), melting of the polar ice caps and unsettling the fabric of our essential ecological processes.

The invited contributions have sought to explore answers to the existential environmental crisis in four clusters: Part I - Prognoses, Part II - Processes, Part III - Problematique and Part IV - Prospects. Notwithstanding best efforts, within the limits of time and space, it has not been possible to cover all the major areas of environmental concern. Some colleagues had to drop out due to compelling personal reasons. Yet it was possible to fill up the gaps at the last moment to reasonably take care of the original design for the EPL Special Issue. It is indeed heartening - nothing short of a miracle - to come out with this EPL Special Issue amidst the global disruption during 2020-2021 caused by Covid-19. It shows that there are 'limits to growth' but no limits to the human capacity to overcome the worst.

The primary objective of the EPL Special Issue has been to sensitize the global audience by firing imaginations of the scholars and the decision-makers to reexamine the current global approaches as well as to explore the future trajectory with new ideas, tools, techniques, processes, 'ecological' frameworks and new international environment institutions. It is a modest effort to challenge the connoisseurs of international law and diplomacy to look ahead at this time of perplexity in the $21^{\text {st }}$ century.

In view of the sheer size of the 21 contributions, they are being published in two installments: (i) Part I - Prognoses and Part II - Processes in EPL Vol.50(6) of 2020 and (ii) Part III - Problematique and Part IV - Prospects in EPL Vol.51(1-2) of 2021.

I dedicate this EPL Special Issue at the altar of our quest for a better common environmental future. 